\title{
Re-evaluation of Petro physical Properties in Yammama Formation at Nasiriya Field
}

\author{
Karrar Hayder Jassim and Jalal A. Al-Sudani
}

Department of petroleum/ University of Baghdad

\begin{abstract}
Nasiriya field is located about $38 \mathrm{Km}$ to the north - west of Nasiriya city. Yammama, a giant lower cretaceous reservoir in Nasiriya field which is lithologically formed from limestone. Yammama mainly was divided into three main reservoir units YA, YB1, YB2 and YB3 and it is separated by impermeable layers of variable thickness. An accurate petro physical evolution of the reservoir is of great importance perform an excellent geological model so that four petro physical properties which are shale volume, porosity, water saturation and permeability was re-evaluated. The volume of shale was calculated using the density and neutron logs (VSH$\mathrm{DN}$ ) rather than using gamma ray log because of presence a uranium content in the formation that makes overestimation of shale volume. Cross plots of Density Neutron logs are used to determine porosity by using IP software, which is correcting automatically Density Neutron logs for the effect of shale. Indonesian equation was used to estimate water saturation for five wells rather than Archie equation in order to consider shale volume. Fuzzy logic was adopted to predict permeability instead of regression analysis (cross plot) because of presence of errors in the results in this method. The results are shown that units YB2 and YB3 have best reservoir quality.
\end{abstract}

Keywords: shale volume, porosity, water saturation, permeability, fuzzy logic

Received on 09/12/2018, Accepted on 14/04/2019, published on 30/09/2019

\section{https://doi.org/10.31699/IJCPE.2019.3.8}

\section{1- Introduction}

To evaluate formation, the determination of shale volume, permeability, porosity and fluid saturation are very essential in the estimation of the hydrocarbon in place. These petro physical properties are important to know the nature of the reservoir, and lead to plan to develop the field. The accurate calculations of petro physical properties in carbonate reservoirs are the most critical point to interpret well $\log [1]$.

Shale is considered most radioactive than sand or limestone. In order to calculate shale volume in reservoir, gamma ray $\log$ can be used. The volume of shale is expressed as a percentage or decimal fraction. When radioactive materials are present in porous reservoir other than shale, for example where sand appears to be shale, overestimation of shale volume from gamma rays log is appear. In this case, shale volume estimation from other $\operatorname{logs}$ are highly recommended to avoid over or under estimation of shale volume [2].

Porosity is an essential property of rock due to measure potential storage volume of hydrocarbons. In carbonate reservoir, porosity ranges about 0.01-0.35 (Schmoker et al. 1985). In addition, Permeability is considered important property of rock because it is measure the ability of rocks to transmit the fluid through it.
The permeability value ranges about $0.01 \mathrm{md}-$ over 1 Darcy. In general, the reservoir that has $0.1 \mathrm{md}$ value of permeability is considered as minimum ability for oil production and when permeability values in the Darcy range, the reservoir consider as highly productive reservoirs [3].

Water saturation value which is one of the most difficult aspects of $\log$ analysis should be estimated, in order to determine the saturation of hydrocarbons in the formations [4].

Yammama Formation is the main Lower Cretaceous carbonate reservoir in southern Iraq. It belongs to the late Tethonian-Aptian cycle. The formation consist of pure limestone, but some dolomitic limestone and shale may exist. Yammama Formation is the second important unit in the Nasiriya field in terms of oil potential. The formation thickness approaches 231m [5].

Yammama Formation is underlined conformably by Sulaiy Formation (the uppermost Jurassic limestone), and overlained by Ratawi formation, which comprises the cap rock for the Yammama Reservoir. Where the Ratawi pinches out, the Zubair Formation directly overlies the Yammama.

The Zubair, Ratawi, and Yammama Formations are periodically coinciding as they are all belonging to the Lower Cretaceous age [6]. 
Yammama Formation has been divided into four reservoir units, based on log characteristics and lithology, designated from top to bottom as (YA, YB1,YB2 and YB3), interbeded by three dense layers act as barriers namely (TGT1, TGT2 and TGT3) [5]. The objective of this study is re-evaluation petro physical properties in previous studies.

\section{2- Petro Physical Analysis}

All log curves were then depth-matched. The available deep resistivity log (ILD) was taken as reference curve. By using IP software, the environmental corrections were made using the current Schlumberger charts on the following logs: RHOB, NPHI, GR, ILD, and MSFL.

\subsection{Shale Volume Determination}

Shale is fine grain rock consisting sizable fraction of silt $\&$ clay. There are many ways to determine the volume of shale in the formation such as from single measurement like gamma ray log or from neutron-density plots [7].

One of the principal uses of GR $\log$ is to calculate the volume of shale where it is measuring the natural radiation generated by the formation. Most isotopes present naturally in the rocks are stable which present in insignificant amount or generate small amount of radiation.

These are the thorium series, the potassium isotope and the uranium-radium isotope. Shales are derived from igneous rocks which have amount of radiant isotopes that emit gamma ray. Igneous rocks are contained quartz, micas and feldspars and the last two contain adequate amount of potassium and occasionally thorium series and uranium-radium isotopes. The Micas and Feldspars alter to clay minerals which the last consider the principle component of shales[8].

In the pure carbonate, thorium will usually be not present because the common thorium ions are insoluble, also potassium will be negligible. The rock may involve uranium. Uranium indicates material of organic origin as organism is extremely good at storing and concentrating uranium.

Uranium ions may be soluble or insoluble depending on ions oxidation state. In shaly carbonate rocks, high gamma ray readings aren't attributed to clay fraction may be related to existing of uranium-radium isotope of organically origin. So that thorium and potassium must present together for shale to be indicated.

The existing of potassium without thorium (with or without uranium) is indicator of remaining algal mats in the formation. It's better to use computing gamma ray log (CGR), which is only the sum of thorium and potassium radiation, and not total gamma ray in order to estimate shale volume [8].
In previous studies (Al-Fattal and Aboud (2001) [9], Omer AL-Ismaily (2011) [10] and Anfal Kareem (2013) [11]), they used total gamma ray log for estimating shale volume without looking for spectral gamma ray log that available only for wells NS-3 and NS-5 and shows for these layers an uranium content not negligible,

Moreover, in some cases, the radioactivity increases in relatively porous layers, conceivably due to the presence of uranium as shown in the fig.1, since the SGR and CGR curves show a significant and not constant separation.

Thus, the use of the total gamma ray for the wells without SGR log may cause an overestimation of shaliness, and anyway a result not comparable with the others.

For these reasons, the VSH was calculated using the density and neutron logs (VSH-DN). The volume of shale from cross plot between Neutron-Density logs was determined, once clean and clay points are indicated which is calculated as the distance of data lies between the clean line and clay point.

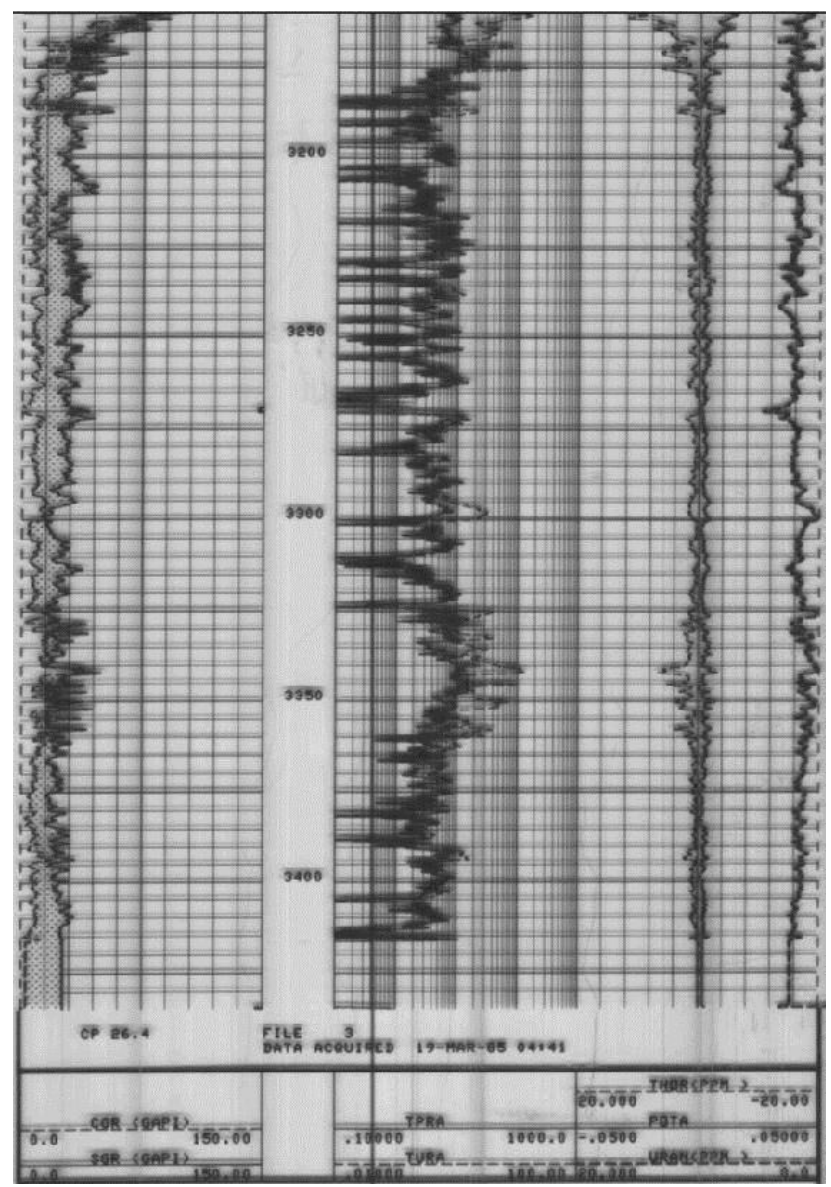

Fig. 1. Well NS-3, Yammama Formation. SGR log

$$
\begin{aligned}
& \text { VCLND } \\
& =\frac{(\text { Dencl } 2-\text { Dencl1 })(\text { Neu }- \text { Neucl1 })-(\text { Den }- \text { Dencl1 })(\text { Neucl2 }- \text { Neucl1 })}{(\text { Dencl2 }- \text { Dencl1 })(\text { Neuclay }- \text { Neucl1 })-(\text { Denclay }- \text { Dencl1 })(\text { Neucl2 }- \text { Neucl1 })}
\end{aligned}
$$

The equation (1) was used by IP software. Where: DenCl1 and $\mathrm{NeuCl} 127$ and $\mathrm{DenCl} 2$ and $\mathrm{NeuCl} 2$ are the density and neutron values for the two ends of the clean line as shown in Fig. 2 [12]. 
Cross plot was plotting for five wells in IP software as shown in fig. 3 . Clean points and clay point was determined for each well as follow:

Clean point 1 as Rho-matrix ranges between 2.68-2.71 $\mathrm{g} / \mathrm{cm}^{3}$ and as NPHI-matrix is $0 \mathrm{~V} / \mathrm{V}$. Clean point 2 as Rho-fluid and NPHI-fluid are 1.

Clay point as Rho-clay ranges between 2.5 to 2.56 $\mathrm{g} / \mathrm{cm}^{3}$ and as NPHI-clay ranges between $0.43-0.45 \mathrm{~V} / \mathrm{V}$.

The equation (1) was used by IP software. Where: DenCl1 and NeuCl127 and DenCl2 and $\mathrm{NeuCl} 2$ are the density and neutron values for the two ends of the clean line as shown in Fig. 2 [12]. Cross plot was plotting for five wells in IP software as shown in fig.3. Clean points and clay point was determined for each well as follow:

Clean point 1 as Rho-matrix ranges between 2.68-2.71 $\mathrm{g} / \mathrm{cm}^{3}$ and as NPHI-matrix is $0 \mathrm{~V} / \mathrm{V}$.

Clean point 2 as Rho-fluid and NPHI-fluid are 1. Clay point as Rho-clay ranges between 2.5 to $2.56 \mathrm{~g} / \mathrm{cm}^{3}$ and as NPHI-clay ranges between $0.43-0.45 \mathrm{~V} / \mathrm{V}$.

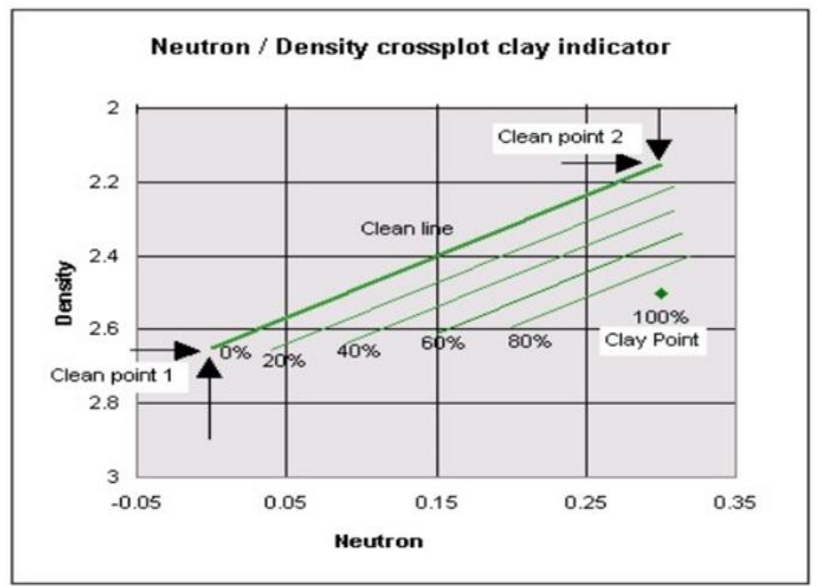

Fig. 2. Neutron / Density Cross Plot [12]

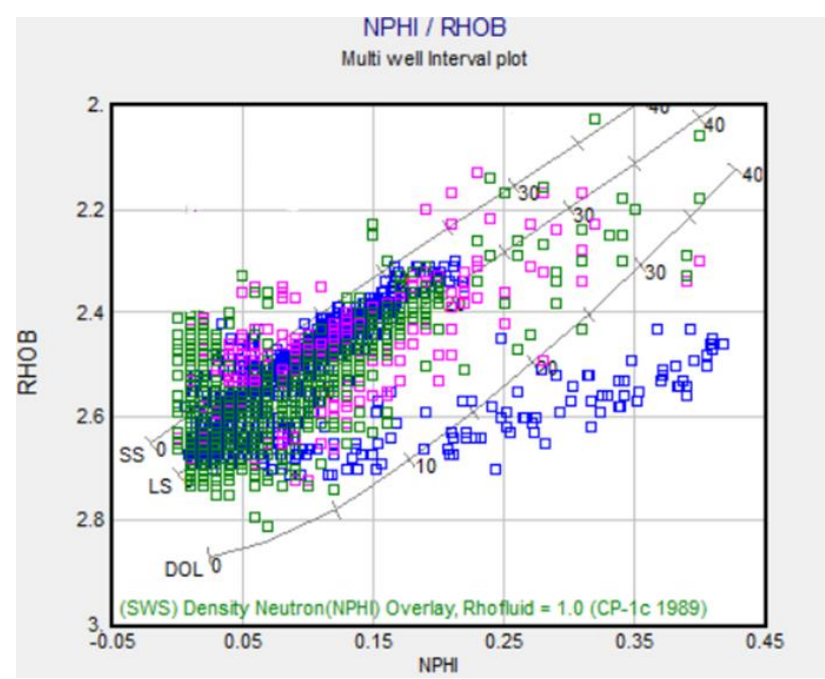

Fig. 3. Density-Neutron Cross Plot for Five Wells by IP software
The results are shown in the fig. 5, 6, 7, 8 and 9 and Table 2.

\subsection{Porosity Determination}

Cross plots of Density Neutron logs are used to determine porosity by using IP software which is correcting automatically Density Neutron logs for the effect of shale. IP software determines porosity by using the cross-plot or equation 2 . The effective porosity is determined by equation 3 .

$\emptyset c p=\sqrt{\frac{\varphi_{N}^{2}+\varphi_{D}^{2}}{2}}$

$\varphi_{e}=\varphi_{T} \times\left(1-V_{c l}\right)$

After porosity was calculated, it is necessary to calibrate it with core porosity.

So for each well, log porosity was plotted against core porosity then the resulting relations were used to calibrate $\log$ porosity. The results are shown in the Fig. 5, Fig. 6, Fig. 7, Fig. 8, Fig. 9 and Table 2.

\subsection{Determination of Water Saturation}

Water saturation is the fraction volume in a given pore space occupied by a water [4]. It's considering one of the important parameters for estimating oil initial in place. In formation evaluation (petro-physical), water saturation can be estimated from several saturation models depending on whether the reservoir is shaly or clean.

In 1942, the first empirical model was building for estimating water saturation in clean, simple, uniform pore system with saline water was Archie equation [13] as shown in equation:

$S_{w}=\left(\frac{a \times R_{w}}{\varphi^{m} \times R_{t}}\right)^{n}$

Water saturation models in shaly formation are the expansion of equation of the Archie with the more term which concerned to shale volume and their associated electrical properties.

One of this expansion equation is Indonesian equation. It was proposed by Poupon and Leveaux in 1971 which used for estimating effective water saturation in shaly formation that is independent of the shale distribution in the reservoir (Bhatt, Helle et al.2001).

This model shows relationship between the resistivity of formation $\&$ the parameters of formation affected it which includes Rw, Rsh, Sw, and Vsh as shown by the following equation [14]:

$\frac{1}{R_{t}}=\frac{V_{s h} S_{w}}{R_{s h}}+\frac{\varphi^{m} S_{w}^{n}}{a R_{w}}$ 
In previous studies, Archie equation was used to calculate waster saturation.so, its evidence that overestimate of water saturation because of presence of shale. In these studies, Indonesian equation was used to estimate water saturation for five wells. The parameters that used were as following:

Rsh was applying as $2.05 \mathrm{Ohm} / \mathrm{m}$ which was derived from thick formation overlying Yammama formation.

$\mathrm{Rw}$ was $0.015 \mathrm{Ohm} / \mathrm{m}$ which was taking from water analysis report.

Rt was taking from ILD log. $\varphi \&$ Vsh was calculated previously.

Table 1. Cementation factor and Tortuosity coefficient [9]

\begin{tabular}{lll}
\hline $\mathrm{a}$ & $\mathrm{m}$ & units \\
\hline 1.52 & 1.44 & $\mathrm{~A}$ \\
1.48 & 1.5 & $\mathrm{~B} 1$ \\
1 & 1.57 & $\mathrm{~B} 2$ \\
1 & 2.1 & $\mathrm{~B} 3$ \\
\hline
\end{tabular}

The results are shown in the fig. 5, 6, 7, 8 and 9 and Table 2.

\subsection{Permeability Estimation}

Permeability is the property of a porous media which is an indication of the ability of porous media to allow fluid to pass through it. In other words, it's considered a measure of ease with that the porous media (rock) will allow the passage of fluids [4].

Permeability takes control the displacement of fluids through the pore space of rocks. It is one of the most essential, most spatially variable, most ambiguous \& so it least predictable transport properties of reservoir [15]. Permeability is commonly calculated from well tests and/or core samples.

However, these measurements are not available in all wells in a reservoir but well logs are available in the majority of wells.so that, accurate and credible calculation of permeability from well-log data involves a significant technical and economic advantages [16].

Laboratory studies have presented which permeability relies upon many parameters such us: pore size and shape, porosity, pore size distribution, clay content, fluid type, and saturation which is a nearly crushing complexity [17].

Permeability is evaluated via correlations among other petro physical properties of rocks. So, various empirical (statistical) models have been introduced to derive permeability from well-log data.

The usual approach to estimating permeability is to cross plot core porosity versus log core permeability and obtain a regression line then this relationship is generated to calculate the permeability for each well of the field.
Unfortunately this assumes that the rock type doesn't change over the interval and permeability is function of porosity only. The method has significant errors but the technique is widely used anyway [7].

Permeability determination in Carbonate reservoir is a complex problem, due to their capability to be tight and heterogeneous, also core samples are usually only available for few wells therefore predicting permeability with low cost and reliable accuracy is an important issue [18].

Also, knowledge of permeability distribution is critical to effective reservoir description. Carbonate reservoirs consist of limestone and dolomite; they are generally less homogeneous than clastic reservoirs and have a wide range of grain size distributions.

Typically carbonates have very low matrix permeability, as low as 0.1 to $1.0 \mathrm{md}$ in some cases, but carbonates often have extensive natural fracture systems [19].

In previous three studies, regression analysis (cross plot) was used to estimate permeability. Because of presence of errors in the results in this method which explain above, it was decided to use other method to estimate permeability.

Fuzzy logic was adopted to predict permeability in this study. Fuzzy logic is one of the ways that create predictions from logs. Regression methods are fundamental tools of the petro physicist but are weak at predicting extremes.

However regression method has the capability to predict and extrapolate values outside the range of the conditioning data-set while fuzzy techniques are confined to look only in the calibrating data-set [20].

In this study, Cuddy method was implemented to estimate permeability for Yammama reservoir. Cuddy achieved fuzzy logic for permeability prediction from well $\log$ in Ula field, Norway.

Fuzzy Probability theory (Probability theory and fuzzy set) was used by Cuddy to estimate permeability.

The 'Fuzzy Logic Curve Prediction' module in Interactive Petro physics (IP) software was used to predict permeability. Porosity (NPHI, RHOB) and volume of shale are best logs to use for permeability prediction.

The 'Fuzzy Logic Curve Prediction' module uses the mathematics (way) of 'Fuzzy Logic' as following [20]:

The 'Input' tab sets up the 'Input curve' names to be used to build a 'Prediction Model'.

Core permeability, porosity (NPHI, RHOB) and shale volume curves for ns-2 were used to build model. The 'Create Model' Tab is used to set up the Model logic and to create. Input curve data are divided into a number of data 'Bins' for use in the Model. 
The number of 'bins' must be between 2 and 100. Two types of 'bin sorting' can be applied:

1- Variable size bins: This is generally used only for discrete input data such as facies numbers.

2- Equal sampled bins: The program will make a preliminary pass through the input data to calculate the data maxima and minima for all curves. IP will then set the bin spacing's so that an equal proportion of data will be placed in each bin.

For each data 'bin' the program calculates the Mean $(\mu)$ and the Standard Deviation for all the associated curves to be used in the prediction.

To make the prediction, the program first calculates the 'fuzzy probability' that an input $\log$ is in a certain bin. The equation is used for this [20]:

$P\left(C_{b}\right)=\sqrt{n_{b}} \times \exp ^{-\left(c-\mu_{b}\right)^{2}\left(2 \times \sigma^{2}\right)}$

Where

$\mathrm{P}(\mathrm{Cb})$ : The probability that curve $\mathrm{C}$ is in bin ' $\mathrm{b}$ '.

$\mathrm{n}_{\mathrm{b}}$ : The number of samples in bin ' $\mathrm{b}$ '.

$\mathrm{C}$ : The input value for curve $\mathrm{C}$.

$\mu_{\mathrm{b}}$ : The mean value for curve $\mathrm{C}$ for bin ' $\mathrm{b}$ '.

$\sigma$ : The standard deviation for curve $\mathrm{C}$ for bin ' $\mathrm{b}$ '.

The probabilities for all the input curves are then combined as follows:

$\frac{1}{P_{b}}=\frac{1}{P\left(C 1_{b}\right)}+\frac{1}{P\left(C 2_{b}\right)}+\frac{1}{P\left(C 3_{b}\right)}+\cdots$

\section{Where}

$\mathrm{Pb}$ : The total probability for bin 'b'.

$\mathrm{P}(\mathrm{C} 1 \mathrm{~b})$ : The probability for curve $\mathrm{C} 1$ for bin ' $b$ '.

The 'Output curves' generated by the model will depend on which 'Output Result' boxes are checked:

1- Most likely': The result with the highest probability.

2- 2nd most Likely': The result with second highest probability.

3- Wt. av. 2 most likely': A weighted average of the two Most Likely results. following equation is used:

$R_{a v}=\frac{R_{m l} \times P_{m l}+R_{s l} \times P_{s l}}{P_{m l}+P_{s l}}$

Where:

$\mathrm{R}_{\mathrm{av}}$ : Average weighted result

$\mathrm{R}_{\mathrm{ml}}$ : Most likely result

$\mathrm{R}_{\mathrm{sl}}$ : Second most likely result

$\mathrm{P}_{\mathrm{ml}}$ : Probability of most likely result

$\mathrm{P}_{\mathrm{sl}}$ : Probability of the second most likely result

The result of permeability estimation of ns-2 in Yammama formation was shown in fig.4. The average weighted result was taken due of goodness matching between $\mathrm{K}_{\text {core }}$ and $\mathrm{K}_{\mathrm{av}}$.

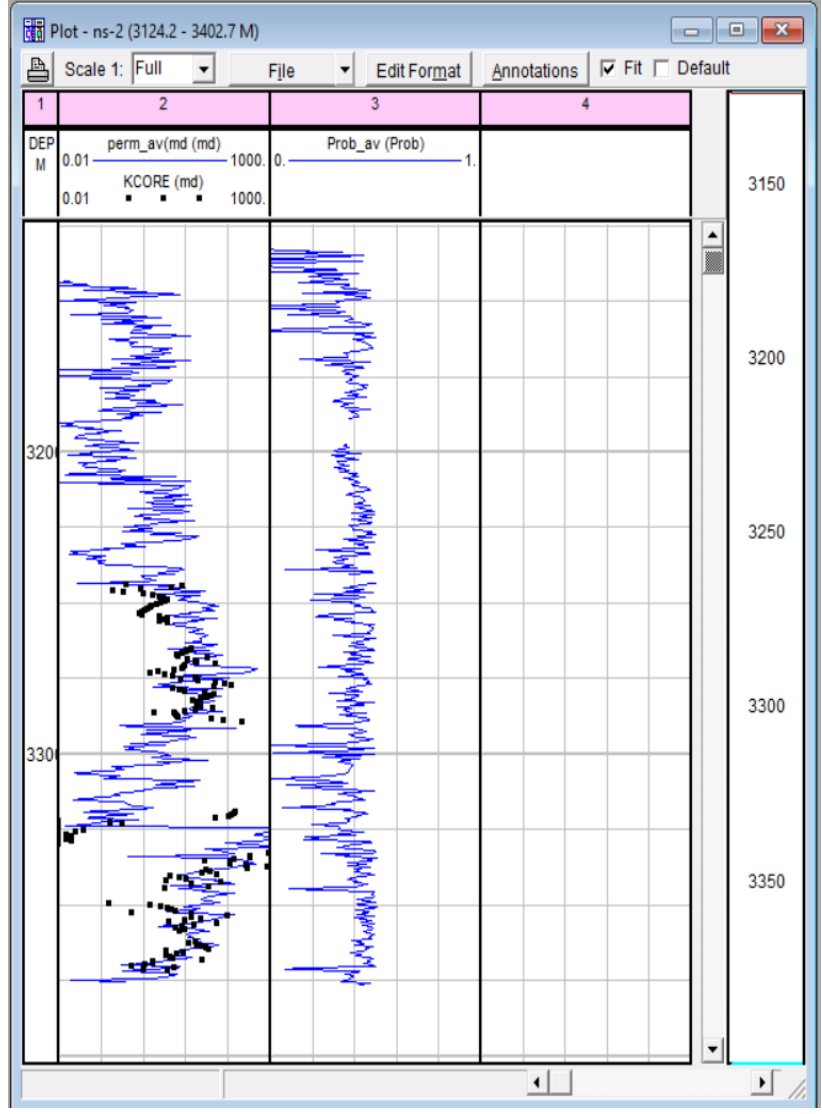

Fig. 4. Result log plot from fuzzy logic

The 'Fuzzy Logic Curve Prediction' module was created for other four wells and it was very good matching between calculated permeability and core permeability.

The final results are shown in the Fig. 5, Fig. 6, Fig. 7, Fig. 8, Fig. 9 and Table 2.

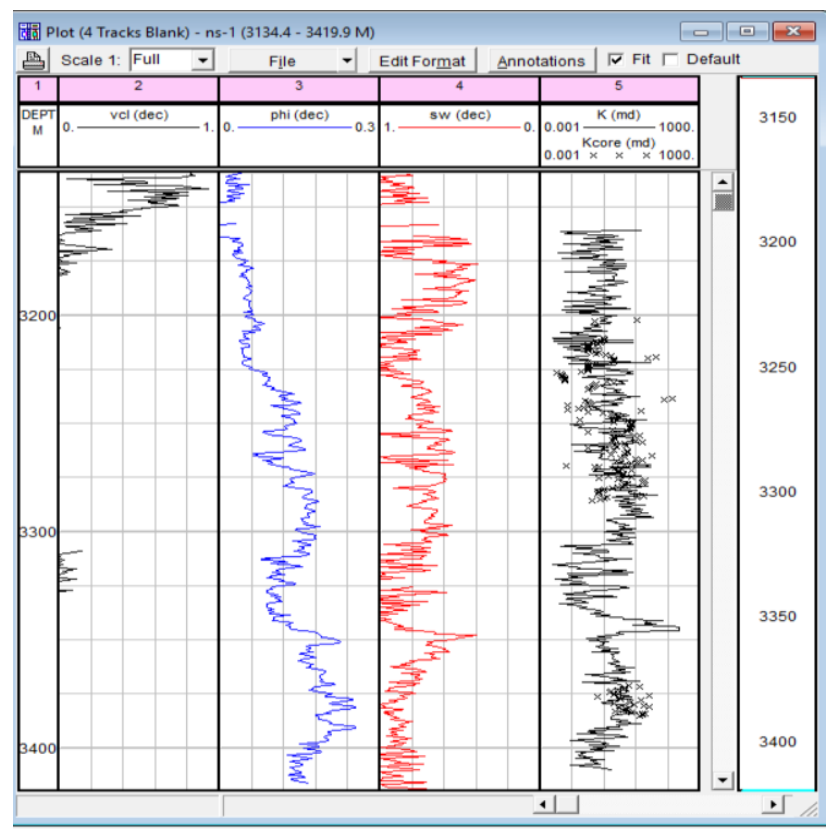

Fig. 5. CPI for NS-1 


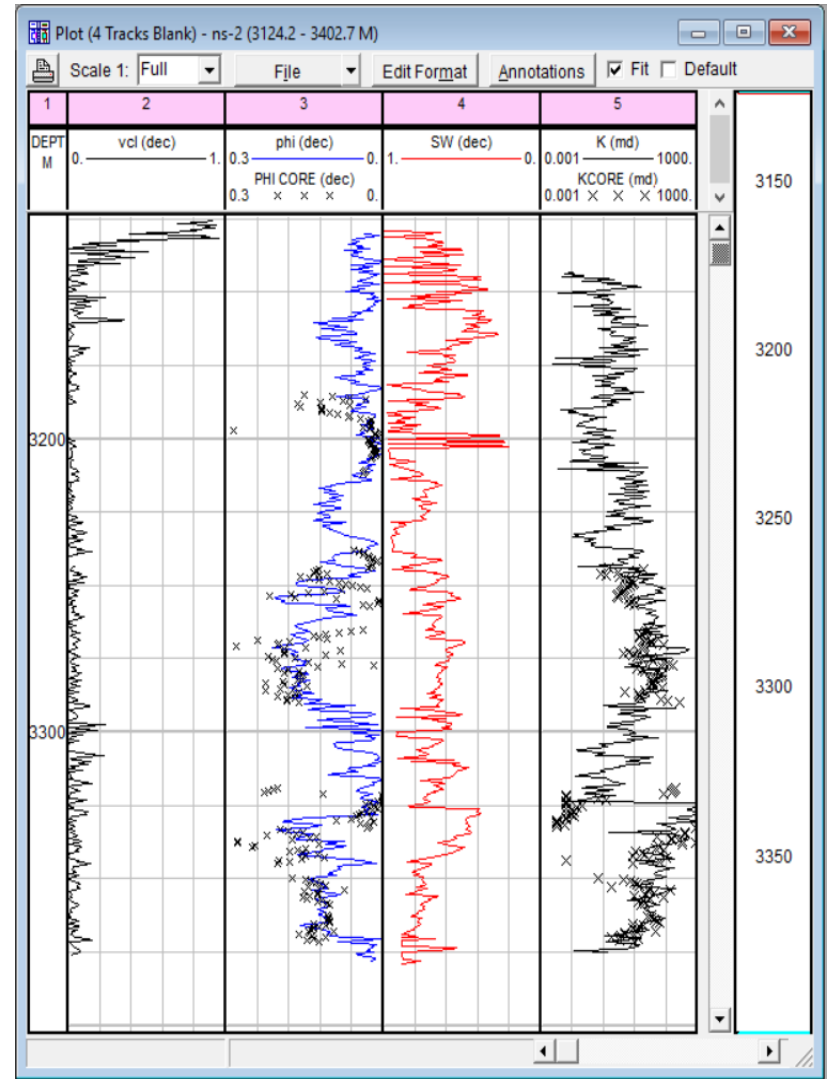

Fig. 6. CPI for NS-2

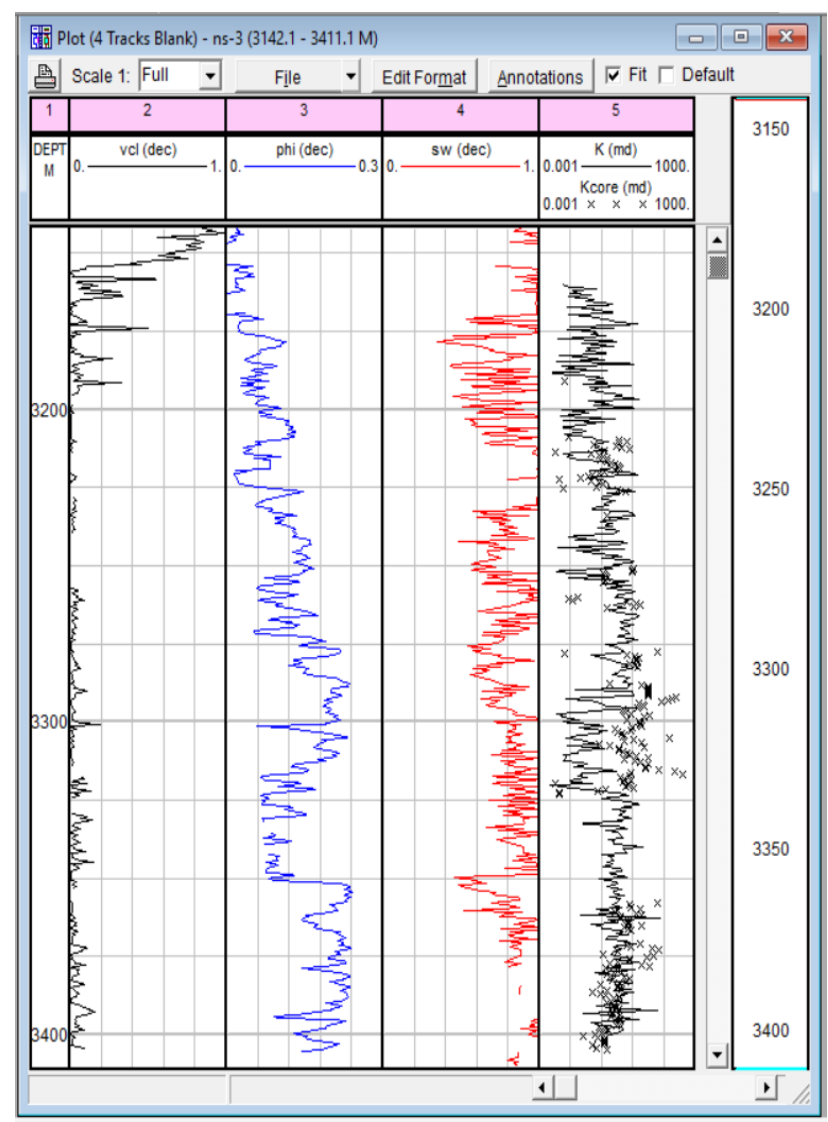

Fig. 7. CPI for NS-3

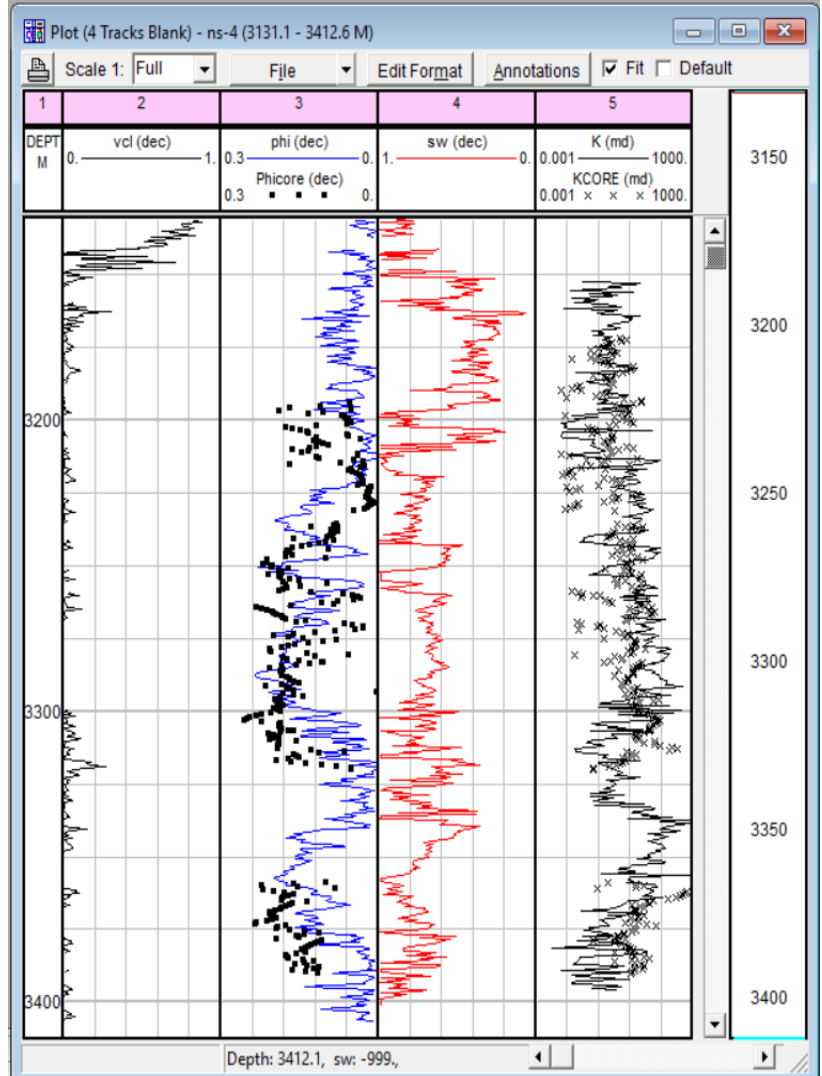

Fig. 8. CPI for NS-4

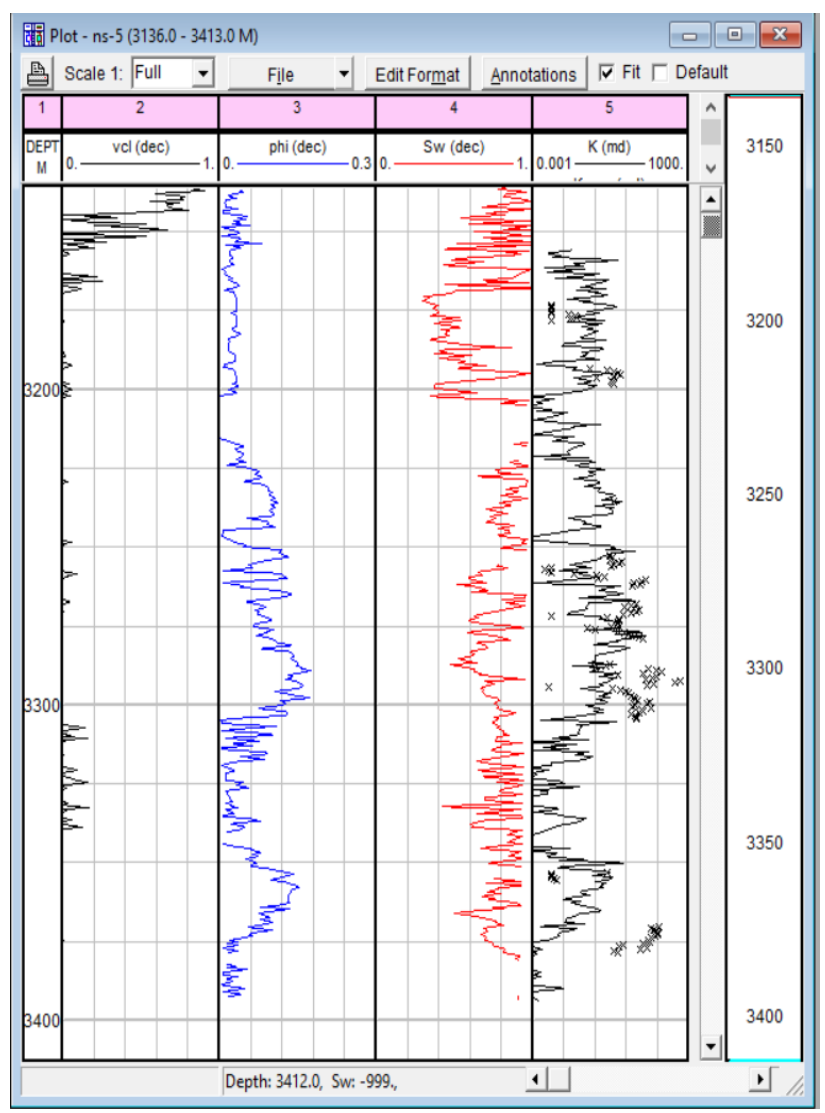

Fig. 9. CPI for NS-5 
Table 2. The Result of Petro Physical Properties Determination for Each well

\begin{tabular}{|c|c|c|c|c|c|}
\hline Wells & Units & $\begin{array}{c}\text { Depth } \\
\text { m }\end{array}$ & Avg. Ø & $\begin{array}{c}\text { Avg. } \\
\text { Sw }\end{array}$ & $\begin{array}{c}\mathrm{K} \\
\text { Arith. Avg } \\
\end{array}$ \\
\hline \multirow[t]{4}{*}{ NS-1 } & YA & $3178-3225$ & 0.08 & 2630. & 0.9 \\
\hline & YB1 & $3242-3270$ & 0.12 & 3210 . & 2.06 \\
\hline & YB2 & 3287 - 3329 & 0.15 & 350. & 6 \\
\hline & YB3 & $3363-3415$ & 0.16 & 450 & 32 \\
\hline \multirow[t]{4}{*}{ NS-2 } & YA & 3157 - 3204 & 0.072 & 210 & 1.15 \\
\hline & YB1 & $3220-3247$ & 0.11 & 290 & 1.9 \\
\hline & YB2 & 3266 - 3306 & 0.16 & 300. & 11 \\
\hline & YB3 & 3341 - 3384 & 0.15 & 40.4 & 58.2 \\
\hline \multirow[t]{4}{*}{ NS-3 } & YA & $3177-3222$ & 0.065 & 290. & 0.92 \\
\hline & YB1 & $3241-3267$ & 0.11 & 360. & 1.1 \\
\hline & YB2 & $3287-3327$ & 0.14 & 380. & 5 \\
\hline & YB3 & $3361-3403$ & 0.17 & 400 & 3 \\
\hline \multirow[t]{4}{*}{ NS-4 } & YA & $3166-3213$ & 0.071 & 200 & 0.65 \\
\hline & YB1 & $3228-3257$ & 0.12 & 330. & 3.3 \\
\hline & YB2 & $3275-3317$ & 0.17 & 350. & 8.8 \\
\hline & YB3 & 3355 - 3392 & 0.14 & 430 & 9 \\
\hline \multirow[t]{4}{*}{ NS-5 } & YA & $3168-3215$ & 0.06 & 260 & 0.61 \\
\hline & YB1 & $3230-3258$ & 0.10 & 340. & 3 \\
\hline & YB2 & 3277 - 3318 & 0.135 & 320. & 15 \\
\hline & YB3 & 3358 - 3389 & 0.16 & 460. & 12 \\
\hline
\end{tabular}

\section{3- Conclusions}

1- The study comprises log interpretation and petro physical properties calculations by using Interactive Petro physical software (IP).

2- It's evidence that the volume of shale is low in Yammama formation because the $\mathrm{V}_{\mathrm{sh}}$ was calculated by using the density and neutron logs (VSH-DN) due to presence organic material which causes overestimation of shale volume which calculated by gamma ray like in the other studies.

3- The porosity for YA unit is considered poor while for YB1and YB2 are fair, but for YB3 is good.

4- Fuzzy logic was adopted to predict permeability in this study which gives best prediction than linear regression.

5- The lower part Yammama reservoir (YB2 \& YB3) has best reservoir quality.

\section{References}

[1] Djebbar Tiab and Erle C. Donaldson, Petro physics, book, Elsevier, $2^{\text {nd }}$ Edition, 2004.

[2] Dewhurst, D.N., Siggins, A.F., Kuila, U., Clennell, M.B., Elastic, Geomechanical and Petrophysical Properties of Shales, StatoilHydro Research Centre, Trondheim, Norway, 2008.

[3] Ekwere J. Peters, "Petrophysics", Department of Petroleum and Geosystems Engineering. The University of Texas, Austin, 2000.
[4] Tarek Ahmed, Reservoir Engineering Handbook, book, Elsevier, Fourth Edition, 2010.

[5] OEC, "An Integrated Geological Evaluation Study of the Nasiriyah Field", (in Arabic), Baghdad, 1993.

[6] Repsol, "Technical Analysis - Business Development - Upstream" Madrid, October- 2008.

[7] E. R. Crain. The Log Analysis Handbook, Pennwell Books, 1986.

[8] Hongqi Liu, Principles and Applications of Well Logging, book, Springer, 2017.

[9] Al-Fattal and Aboud, A comprehensive reservoir study of Nasiriya field/ Yammama formation, Ministry Of Oil, Reservoir and Field Development Department, 2001.

[10] Omer AL-Ismaily, Study of Reservoir Properties of YAMAMA Formation in NASSIRYA Field and Its Relation with Oil Production, thesis, The College of Science, University of Basra, 2011.

[11] Anfal Kareem, Reservoir study of Yammama formation in Nasiriya Field by using modern software, thesis, Petroleum Engineering, Baghdad University, 2013.

[12] Schlumberger, "Interactive Petrophysical Fundamental, Version 3.1", 2005.

[13] Archie, G. E., the Electrical Resistivity Log as an Aid in Determining Some Reservoir Characteristics. Petroleum Transactions of the AIME, 1942.

[14] Poupon, A. and Leveaux, J., Evaluation of Water Saturation in Shaly Formations. The Log Analyst, 12, $\underline{1-2,1971 .}$

[15] W. Al-Qattan and A. Al Mohammed, "Permeability Prediction By Classical and Flow Zone Indictor (FZI) Methods for an Iraqi Gas Field", ijcpe, vol. 18, no. 3, pp. 59-65, Sep. 2017.

[16] S. Ameri, D. Molnar, S. Mohaghegh, and K. Aminian. Permeability evaluation in heterogonous formations using geophysical well logs and geological interpretations. In SPE Western Regional Meeting, Anchorage, Alaska, 1993.

[17] Schlumberger. Log Interpretation Principles/Applications. Houston, 1989.

[18] D. Alobaidi, "Permeability Prediction in One of Iraqi Carbonate Reservoir Using Hydraulic Flow Units and Neural Networks", ijcpe, vol. 17, no. 1, pp. 1-11, Mar. 2016.

[19] S. A. Lazim, S. M. Hamd-Allah, and A. Jawad, "Permeability Estimation for Carbonate Reservoir (Case Study/ South Iraqi Field)", ijcpe, vol. 19, no. 3, pp. 41-45, Sep. 2018.

[20] Cuddy, S. J. , The Application of the Mathematics of Fuzzy Logic to Petro physics. Paper S. 38th Annual Symposium of the SPWLA, 1997. 


\title{
اعادة تقييم الخواص البتز وفيزيائية لتكوين اليمامة في حقل الناصرية
}

\author{
كرار حيدر و جلال عبدالواحد
}

قسم هنسة النفط/جامعة بغداد

الخلاصة

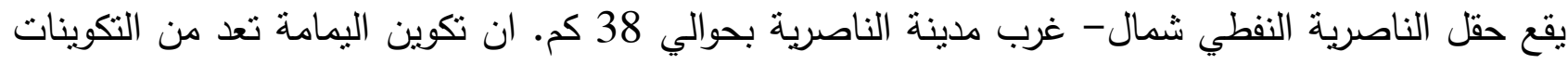

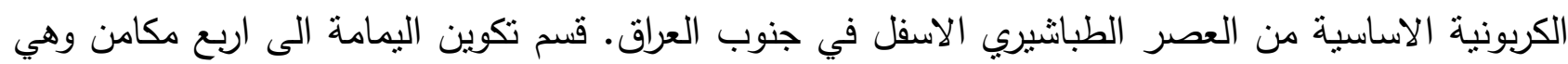
YA, YB1,YB2,YB3 ثلاثة دراسات اجريت على التكوين اليمامة في حقل الناصرية. ان دقة نقييم الخواص البتر وفيزيائية تعتبر من

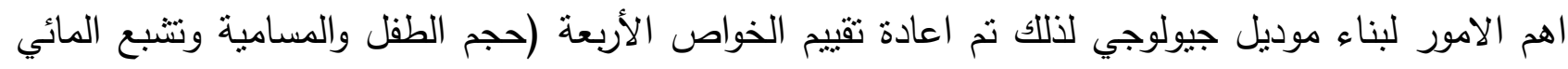
والنفاذية). في الدراسات السابقة نم استخدام مجس اشعة كاما لحساب حجم الطفل بدون الاخذ بنظر الاعتبار تسجيل مجس اشعة كاما الطبيعي المنوفر لبئر ناصريه الثالث والخامس حيث تبين وجود طبقات تحمل اليورانيوم لذلك تم حساب حجم الطفل من مجس الكثافة والنيوترون باستخدام برنامجادا. تم حساب المسامية من لن مجس الكثافة والنيوترون المصححة لتأثير الطفل. ايضا في الدراسات السابقة تم حساب التثبع المائي باستخدام معادلة Archie بدون الاخذ بنظر الاعتبار الزيادة الحاصلة في قيم النتبع نتيجة تأثثر حجم الطفل. تم استخدام

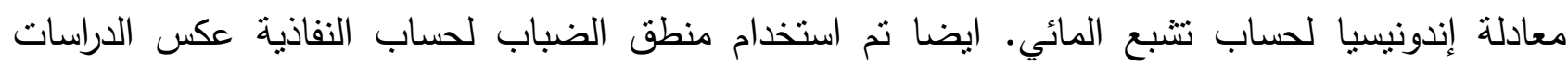
السابقة التي تم استخدام تحليل الانحدار قليل الدقة.

الكلمات الدالة: حجم الطفل، المسامية، التثبع المائي، النفاذية، منطق الضباب. 